\title{
Effect of Solar Eclipse on Cell Division in the Meristematic Root Cells of Allium sativum L.
}

\author{
N. K. Soni, Premlata Oswal and S. K. Yadav \\ Department of Botany, University of Saugar, SAGAR, 470003, India
}

Received May 6, 1980

Our entire atmosphere (-subject to the earth's magnetic field) could be considered as a massive mixture of electrons, ions, neutral particles and a number of trace species, which are the result of complex reactions and interaction of the atmosphere with solar radiation (Mitra 1980). Any sizable change in the ionosphere/ stratosphere, electromagnetic field and/or radiation would effect the life on the earth. A total eclipse of the sun offers opportunities for numerous scientific observations, many of which are possible at no other time. With this in view attempts lwere made to determine cell division in Allium sativum L. roots when the sun was Igradually obscurred during Solar Eclipse over India on 16 th February 1980.

\section{Materials and methods}

The Allium sativum bulbs of same age were collected from local market and three sets of bulb scales were made for these observations. The scales of each set were subjected to a pre-germination period of $72 \mathrm{~h}$ in tap water, so as to get fresh root crop and were then exposed to different conditions of the investigation.

Pre-germinated scales of first set were exposed to sunlight of a normal day for $12 \mathrm{~h}$, from $06.00 \mathrm{AM}$ to $06.00 \mathrm{PM}$ in the first week of February. Simultaneously a set of pre-germinated scales was also kept in the laboratory (-in diffused light) as control. Another set of pre-germinated scales was maintained in several replicates and was exposed to light of Solar Eclipse's day (i.e. 16th Feb. 1980, from 06.00 $\mathrm{AM}$ to $06.00 \mathrm{PM})$. The total duration of eclipse was about $150 \mathrm{~min}$ and that of totality $(80 \%)$ was 2 min and $51 \mathrm{sec}$.

Exposed samples (scales of first set and scales of Solar Eclipse's day set) were then kept for $72 \mathrm{hr}$ in laboratory conditions for recovery immediately after aforesaid exposures. After recovery meristematic tips of roots of the same length from each set were fixed in acetic-alcohol $(1: 3 \mathrm{v} / \mathrm{v})$ for $24 \mathrm{~h}$ and were then observed for mitotic index and mitotic abnormalities.

Root tip squashes were made in $2 \%$ aceto-orcein according to the schedule given by Sharma and Sharma (1965). Results are expressed as mean \pm standard error together with ' $t$ ' significance test for mitotic index and as percentage for different stages and chromosomal abnormalities. All types of dividing cells were included i.e. prophase, metaphase, anaphase and telophase. The resting cells were taken as non-dividing. Photomicrographs were 'taken' from temporary preparations. 


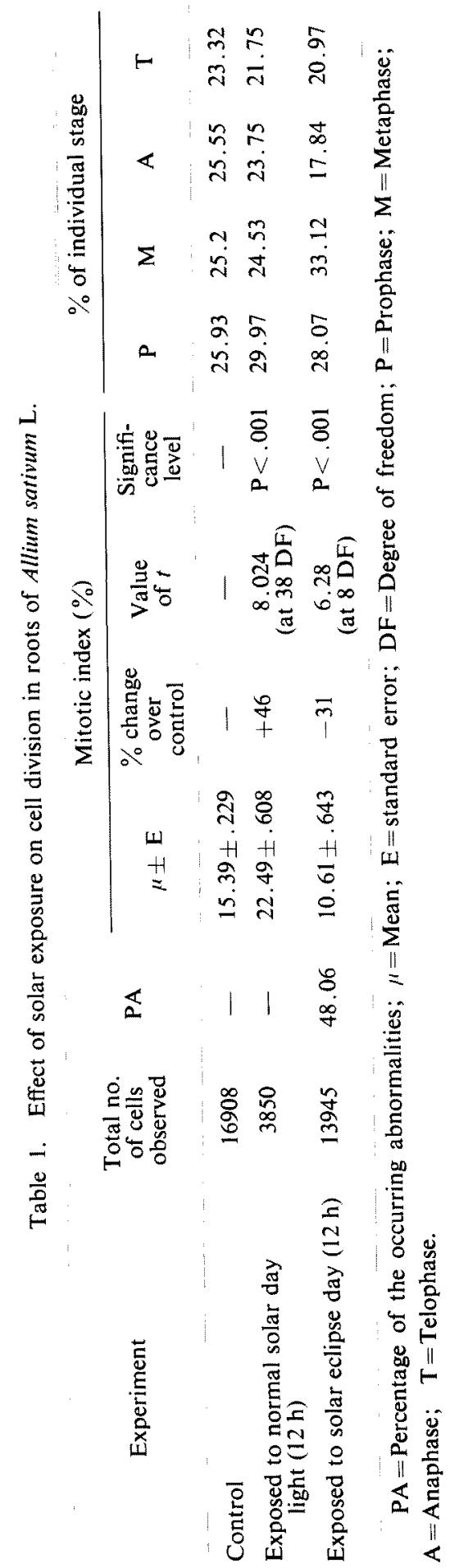




\section{Results}

The data have been presented in Tables 1 and 2 . It will be seen that there was an enhancement in the frequency of dividing cells in the meristematic root tips when exposed to normal solar day light as the mitotic index in these samples was higher (22.49 \pm 0.608$)$ in comparison to that of control. The M.I. in the control was $15.29 \pm 0.229$, while on the other hand this was declined upto $10.61 \pm 0.643$ in the eclipse exposed samples giving a reduction of about $31 \%$ over control (Table 1). Both of these effects as observed in normal day light exposed (NDLE) and eclipse's day light exposed (EDLE) samples were highly singificant statistically $(\mathrm{P}<0.001)$.

On the analysis of different stages of cell division (Table 1) the occurrence of pro-, meta-, ana-, and telophase in control samples was 25.93, 25.2, 25.55 and 23.32 percent respectively. In NDLE samples, the occurrence of prophase was slightly higher and that of rest of the mitotic stages was lower in comparison to control.

Table 2. Type and frequencies of aberrations at different stages of mitosis in meristematic root tip cells of Allium sativum L. exposed to solar eclipse's day light

\begin{tabular}{lrlcccccc}
\hline \multirow{2}{*}{ Mitotic stage } & \multicolumn{7}{c}{ Percentage of the different types of abnormalities } \\
\cline { 2 - 9 } & PAES & Sticki. & $\begin{array}{l}\text { Scatt./ } \\
\text { Frag. }\end{array}$ & Lag. & $\begin{array}{c}\text { Unequal } \\
\text { dis. }\end{array}$ & Bridge & Ero. & Stathmo. \\
\hline Prophase & 7.88 & - & - & - & - & - & 7.88 & - \\
Metaphase & 78.08 & 29.85 & 44.46 & 3.55 & - & - & 0.21 & - \\
Anaphase & 6.76 & - & - & 2.7 & 1.45 & 2.32 & - & 0.29 \\
Telophase & 71.61 & - & - & 0.33 & - & - & 71.28 & - \\
\hline
\end{tabular}

There were no chromosomal aberrations in the root tip cells of control and normal day light exposed samples.

PAES $=$ Percentage of the occurring abnormalities at each stage.

The EDLE samples showed 28.07, 33.12, 17.84 and 20.97 percent occurrence of pro-, meta-, ana- and telophase.

Cells were scored for chromosomal abnormalities. Results are presented in Table 2. It may be seen that the chromosomal abnormalities were evident only in those meristematic root tip cells of $A$, sativum which were exposed to solar eclipse's day light.

The stages which were more susceptible to the eclipse's effect appear to be metaphase and telophase, where 78 and 71 percent chromosomal abnormalities were recorded. Of these scattering/fragmentation, stickiness and eroded chromosomes were significant (Figs. 1-3, 7, and 10). Other observations though in small percentage were chromatid bridges, unequal distribution of chromosomes, laggards, tetrapolarity, stathmoanaphase and giant cells (Figs. 4-6, 8 and 9). Giant cells were double the size of the ordinary meristematic root cells. Besides these abnormalities, reductional grouping and nuclear fragmentation were also evident in some cells (Figs. 11 and 12). 


\section{Discussion}

The effect of ionizing radiation on mitosis has been studied in many materials mainly by irradiating the rapidly dividing cells of the root tips or by irradiating the pollen tubes on germination of pollen grains. The effect observed in these studies have been classified as 'primary effects' (Albert and Politzer 1923 and 1924,
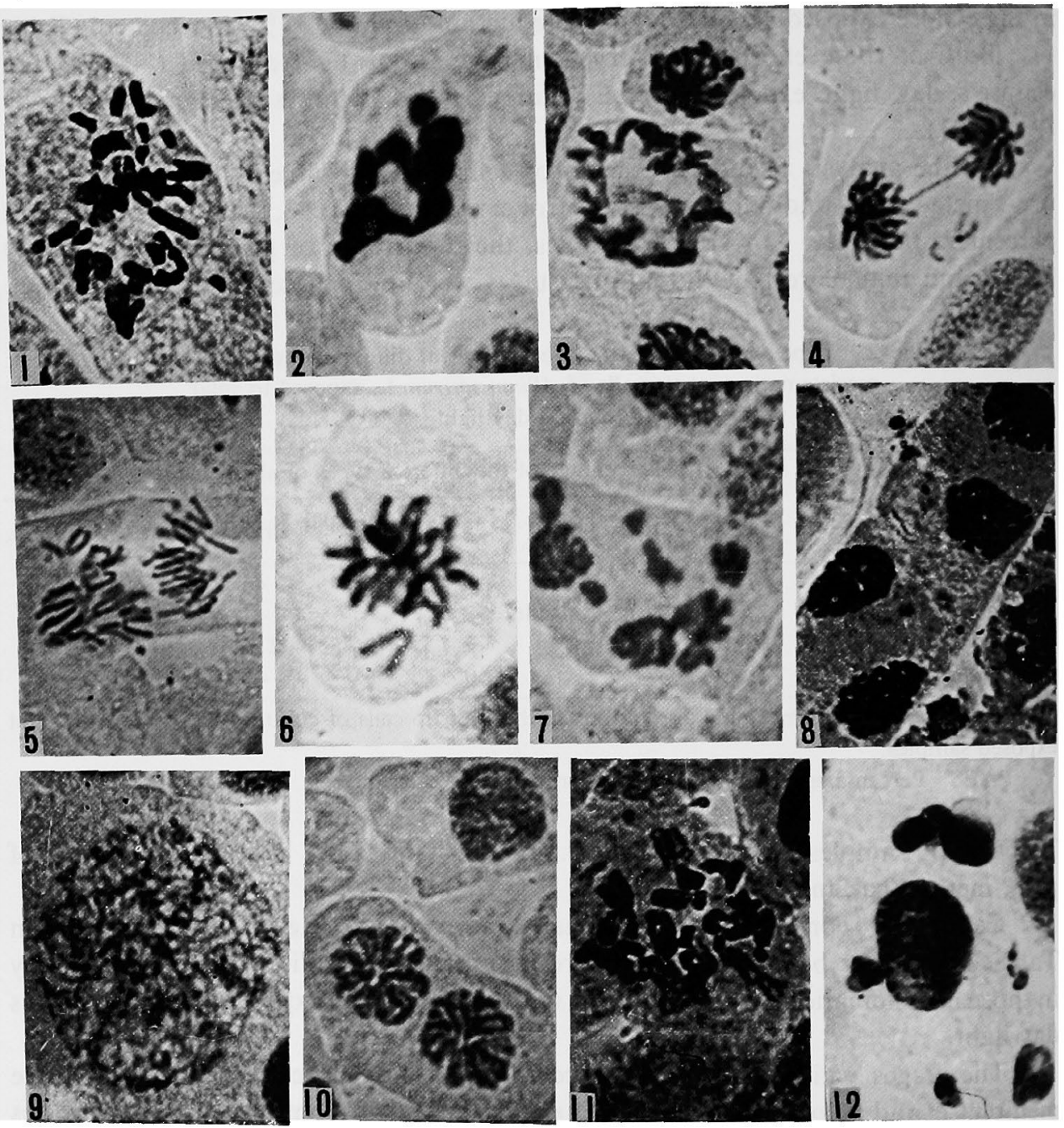

Figs. 1-12. 1, scattering/fragmentation. 2, 3 and 7, stickiness. 4, chromatid bridge with lagging chromosomes at anaphase. 5, unequal distribution. 6, laggard at metaphase. 8, tetrapolarity. 9 , giant cell. 10, erosion at anaphase. 11 , reductional grouping. 12, nuclear fragments.

Marquardt 1938, and Sax 1941) for what is usually described as physiological effects and 'secondary effects' for what is interpreted as structural changes (Lea 1946). The physiological effects are generally manifested by cells which are already in division at the time of irradiation and the cells generally recover from these physiological effects. The mitotic inhibition, stickiness and clumping of chromosomes are the 
outcomes of physiological effects. The structural changes are shown by cells which enter division from interphase after receiving radiation and not generally by cells which are already in division. These structural changes include chromatid and chromosome break at different positions on the chromosome leading to various structural rearrangements of chromosomes by union of broken ends. These effects are seen after a period of 27-30 h (Sax 1941).

In the light of the above it is remarkable to note that in the present study the dividing cells of the roots exposed to solar eclipse's day light also exhibit similar abnormal chromosome behaviour such as the physiological effects and structural changes revealed by the actively dividing irradiated cells of the root tips in other plants studied previously. Solar eclipse appears to disrupt the normal functioning of cell by inhibiting the process of cell division and by producing chromosomal anomalies. The inhibition of mitotic division suggests that solar eclipse has antimitotic activity and effects some vital functional unit of cell.

The common mitotic abnormalities in the present study are the stickiness and scattering of chromosomes, fragments, bridges, laggards and presence of giant cells.

The most common abnormalities are stickiness and scattering. According to Darlington (1942) stickiness is due to the disturbance in the nucleic acid metabolism in the cell. Disturbance in the mitotic spindle may result in the scattering of chromosomes. Inhibition of mitotic spindle by colchicine (Davidson and MaCleod 1966) and disturbed mitotic spindles by radiation (Marquardt 1938) and by various chemicals (Östergren 1950, Patua and Patil 1951) have been observed.

Other cytological abnormalities included, bridges, fragments and laggards. Presence of bridges itself indicates that there has been some amount of chromosome breakage. Several hypotheses have been offered to explain the mechanism of chromosome breakage by radiations and chemicals in intact tissues (Revell 1958, Wolff 1963). It is quite possible that all these mitotic irregularities in the cells can be induced partly by the endogenous 'mitotic poisons' which may arise from the break down of micro and macro molecules especially enzymes and nucleoproteins in the cytoplasm by solar eclipse day light exposure. These mitotic poisons may cause 'metabolic imbalance' which may interfere with the synthesis, state and structure of nucleic acids inducing physiological effects and structural changes in the chromosomes during cell division which may lead to mitotic delay and mitotic inhibition.

There are a few reports on the formation of giant cells, as in the present study, in irradiated roots of Vicia faba (Gray and Scholas 1951) and V. ervilia (Shaikh and Godward 1972). Tolmach and Marcus (1960) have suggested that giant cells may result from the ultimate failure of cell division process. The mechanism of giant cell formation, however, has not been explained thoroughly (Ishihara and Kumatori 1966).

The stimulation in mitotic rate as induced by normal day light exposure in the present study is similar to the reports of Thompson (1954). While working on the effect of light on cell division in oats and peas seedlings he reported an acceleration of whatever processess of growth are going on during and immediately after 
the action of light stimulus.

\section{Summary}

Attempts were made to determine the effects of solar eclipse (80\% totality, 16th Feb. 1980) on cell division process in meristematic root tips of Allium sativum L. Normal day light stimulated cell division. Solar eclipse was found to produce inhibitory effects on mitosis. Eclipse's day light exposures induced various mitotic chromosomal aberrations i.e. scattering/fragmentation, stickiness, eroded chromosomes, chromosomal bridges, laggards and stathmoanaphase.

\section{Acknowledgement}

The authors are thankful to Professor G. P. Mishra, Head, Department of Botany, University of Saugar, Sagar for providing laboratory facilities and encouragements.

\section{References}

Albert, W. and Politzer, G. 1923. Influence of X-rays on cell division Part I. Arch. Mikr. Anat, 100: 83.

- and Politzer, G. 1924. Influence of X-rays on cell division Part II. Arch. Mikr. Anat. 103: 284.

Darlington, C. D. 1942 . Chromosome chemistry and gene action. Nature 149 : 66-69.

Davidson, D. and Ma Cleod, R. D. 1966. Changes in mitotic indices in roots of Vicia faba I. Antagonistic effect of colchicine and IAA. Chromosoma 18: 421-437.

Gray, L. H. and Scholas, M. E. 1951. The effect of ionizing radiations on the broad bean root. Part 8: Growth rate studies and histological analysis. Brit. J. Radiol. 24 (279): 176-180.

Ishihara, T. and Kumatori, T. 1966. Polyploid cells in human leukocytes following in vivo and in vitro irradiation. Cytologia 33: 59-68.

Lea, D. E. 1946. Action of Radiation on Living Cells. Cambridge University Press pp. 193.

Marquardt, H. 1938. Die Röntgenpathologie der Mitose. Z. Bot. 32: 301-482.

Mitra, A. P. 1980. Effects of solar eclipse on the earth's atmosphere. Science Today (February): 51-54.

Östergren, G. 1950. Cytological standards for the quantitative estimation of spindle disturbance. Hereditas 36: 371-382.

Patua, K. and Patil, R. P. 1951. Mitotic effects of sodium nucleate in root tips of Rheo discolour Hans. Chromosoma 4: 740-502.

Revell, S. H. 1958. A new hypothesis for the interpretation of chromatid aberrations and its relevance to theories for the mode of action of chemical agents. Ann. N. Y. Acad. Sci. 68: $802-810$.

Sax, K. 1941. Types and fragments of chromosomal aberrations induced by X-rays. Cold Spring Harb. Symp. Quant. Biol. 9: 93-101.

Sharma, A. K. and Sharma, A. S. 1965. Chromosome Techniques. Theory and Practice. Butterworth \& Co (Publishers) Ltd. London.

Shaikh, M. A. Q. and Godward, M. B. E. 1972. The mitotic consequences of radiation induced chromosome breaks in Lathyrus sativus and Vicia ervila. Cytologia 37: 489-495.

Thompson, B. F. 1954. The effect of light on cell division and cell elongation in seedlings of oats and peas. Am. J, Bot, 41: 326-332.

Tolmach, L. J. and Marcus, P. I. 1960. Development of X-ray induced giant Hela cells. Exptl. Cell Res. 20: 350-360.

Wolff, S. 1963. Radiation Induced Chromosome Aberration. Columbia University Press, N. Y. London. 